\title{
Optical Coherence Tomography Angiography
}

\author{
Dita Mintardi $^{1 *}$, AK Ansyori ${ }^{1}$, Ramzi Amin $^{1}$ \\ ${ }^{1}$ Department of Ophthalmology, Faculty of Medicine, Universitas Sriwijaya, Indonesia \\ *Correspondence author email: dita.mintardi@gmail.com
}

\begin{abstract}
Optical Coherence Tomography Angiography (OCTA) is a new high-resolution imaging method for visualizing retinal and choroidal circulation without any dye injection By detecting intravascular flow quickly when needed and being able to repeat images, as often as needed, without risk to patients, doctors will value OCTA as one of the most important applications of OCT imaging because of its ability to offer precise visualization of intravascular flow in the inner retina layer and outside, as well as the inner choroid. OCTA uses high-speed structural OCT imaging and provides three-dimensional data about microvascular structures, enabling visualization of the en face apart from the retinal capillary plexus and choriocapillaris, combined with co-registered en face and cross-sectional structural OCT. Although OCTA is a strong modality, it can have imaging artifacts and provide information that is inherently more complex than structural OCT alone. Successful interpretation of OCTA findings requires an understanding of how OCTA works, the relationship of various ocular pathologies to its angiographic features, and integrated assessment of angiographic and structural OCT data.
\end{abstract}

Keywords: optical coherence, tomography, angiography

\section{Introduction}

Optical Coherence Tomography Angiography (OCTA) is a new high-resolution imaging method for visualizing retinal and choroidal circulation without any dye injection By detecting intravascular flow quickly when needed and being able to repeat images, as often as needed, without risk to patients, doctors will value OCTA as one of the most important applications of 
OCT imaging because of its ability to offer precise visualization of intravascular flow in the inner retina layer and outside, as well as the inner choroid. An added benefit of this imaging strategy is that the same image obtained during OCTA can also be seen as a typical OCT B-scan. As the quality of OCTA imaging improves and its availability becomes wider, it is predicted that this non-invasive technology will become a new standard for imaging both blood vessels and anatomy of the retina and choroid. ${ }^{1}$

OCTA uses high-speed structural OCT imaging and provides three-dimensional data about microvascular structures, enabling visualization of the en face apart from the retinal capillary plexus and choriocapillaris, combined with co-registered en face and cross-sectional structural OCT. Although OCTA is a strong modality, it can have imaging artifacts and provide information that is inherently more complex than structural OCT alone. Successful interpretation of OCTA findings requires an understanding of how OCTA works, the relationship of various ocular pathologies to its angiographic features, and integrated assessment of angiographic and structural OCT data. ${ }^{1,2}$

The purpose of writing this paper is to know, know the principles of work, technological developments, and help users interpret OCTA images.

\section{Macula Anatomy}

The macula is part of the posterior retina. The macula border is histologically a central area of the retina that contains xanthophyll (yellow) pigments and two or more layers of ganglion cells. The term macula is derived from the word "macula lutea" which means yellow spots where the yellow color in the central retina is closely related to the presence of xanthophyll pigments located mainly in the layer of Henle fibers. Two main pigments are identified, namely zeaxanthin and lutein, the proportions vary depending on the distance from the fovea. In the central area $(0.25 \mathrm{~mm}$ from the fovea), the ratio of lutein and Zeaxantin is 1: 2.4 while in the peripheral area (2.2 - $8.75 \mathrm{~mm}$ from the fovea) the ratio becomes $2: 1$. The variation of this pigment ratio is related to ratio of stem cells and cone cells. Lutein is more concentrated in a dense area of cone cells. These carotenoids have antioxidant functions and also function as filters for the wavelength of blue light, so as to prevent damage.,

The diameter of the macula is around 5-6 $\mathrm{mm}$ and is limited by branches of the temporal retinal vessels. Histologically it consists of a thin basal lamina, muller cells, and cone cells. In 


\section{SRIWIJAYA JOURNAL OF OPHTHALMOLOGY}

ध्रु०

the central area of the macula there is the foveal avascular zone (FAZ), a small concave-shaped area without retinal capillaries and consists of cone cells. ${ }^{3,4}$

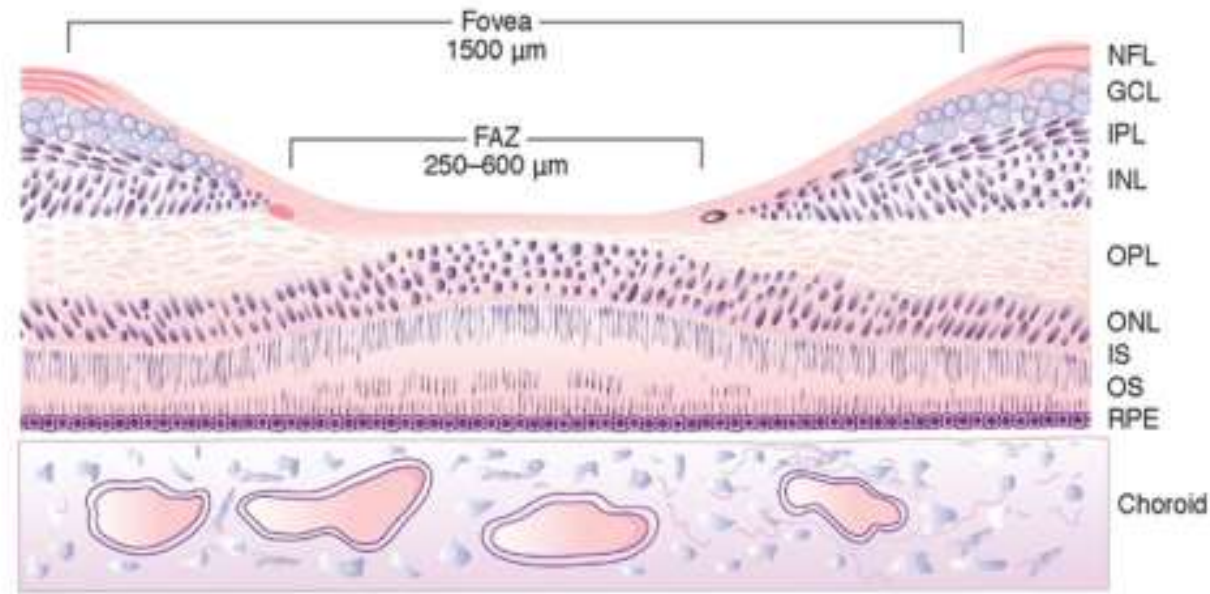

Schematic description of fovea. FAZ: Fovea Avascular Zone; GCL: Ganglion Cell Layer; INL: Inner Nuclear Layer; IPL: Inner Plexiform Layer; IS: Inner Segment of photoreceptors; NFL: Neuro Faber Layer; ONL: Outer Nuclear Layer; OPL: Outer Plexiform Layer; OS: Outer Segment of photoreceptor; RPE: Retinal Pigment Epithelium. Quoted from Fundamentals and Principles of Ophthalmology. American Academy of Ophthalmology. Section 2. 2015-2016.

The central area of the macula which has a diameter of $1.5 \mathrm{~mm}$ and is a depression on the surface of the inner retina is called the fovea. In this area there are no blood vessels and stem cells, here there is the highest concentration of cone cells. The number of cone cells decreases dramatically in the peripheral region, whereas in the peripheral photoreceptor stem cells have the highest density which is around 160,000 cells $/ \mathrm{m}^{2}$. The base of the middle part of the fovea is a foveola with a diameter of $0.35 \mathrm{~mm}$ and a small depression in the middle of the foveola called umbo. The parafovea area is an area of $0.5 \mathrm{~mm}$ width where the ganglion cell layer, the inner nuclear layer, and the thickest outer plexiform layer. The area that surrounds it with a width of $1.5 \mathrm{~mm}$ is called the perifovea zone which is the outer border of the macula. ${ }^{3,4}$ 


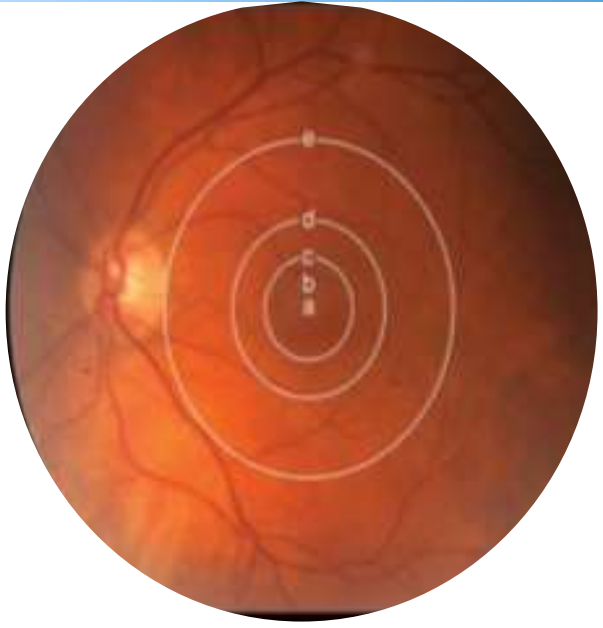

Image of Macular Anatomy.

a: umbo; b: foveola; c: fovea; d: parafovea; e: perifovea;

Quoted from Retina and Vitreous. American Academy of Ophthalmology. Section 12. 2015-2016

\begin{tabular}{|c|c|c|c|}
\hline Term & Synonym & Histologic Definition & Clinical Observation (Size) \\
\hline Macula & $\begin{array}{l}\text { Posterior pole } \\
\text { Area centralis }\end{array}$ & $\begin{array}{l}\text { Contains } 2 \text { or more ganglion } \\
\text { cell layers }\end{array}$ & $\begin{array}{l}\text { Area between vascular arcades } \\
5.5 \mathrm{~mm} \text { in diameter centered } \\
3.0 \mathrm{~mm} \text { temporal and } \\
0.8 \mathrm{~mm} \text { inferior to the center } \\
\text { of the optic disc }\end{array}$ \\
\hline Fovea & Fovea centralis & $\begin{array}{l}\text { A depression in the inner } \\
\text { retina, has a margin, slope, } \\
\text { and floor, the photoreceptor } \\
\text { layer of which is entirely } \\
\text { cones }\end{array}$ & $\begin{array}{l}\text { A concave central retinal } \\
\text { depression seen on slit- } \\
\text { lamp examination } 1.5 \mathrm{~mm} \\
\text { in diameter (about } 1 \mathrm{disc} \\
\text { diameter, or } 5^{\circ} \text { ) }\end{array}$ \\
\hline Foveola & & $\begin{array}{l}\text { The floor of the fovea features } \\
\text { cones only, arranged in the } \\
\text { shape of a cake (gatteau } \\
\text { nucléaire), where the inner } \\
\text { nuclear layer and yanyliun } \\
\text { cell layer are laterally } \\
\text { displaced }\end{array}$ & $\begin{array}{l}0.35 \mathrm{~mm} \text { in diameter, usually } \\
\text { smaller than the foveal } \\
\text { avascular zone }\end{array}$ \\
\hline Umbo & $\begin{array}{l}\text { Fixation } \\
\text { Light reflex }\end{array}$ & $\begin{array}{l}\text { Small }(150-200 \mu m) \text { center } \\
\text { of the floor of the foveola; } \\
\text { features elongated cones } \\
\text { forming a bouquet of cones }\end{array}$ & $\begin{array}{l}\text { Observed point corresponding } \\
\text { to the normal light reflex but } \\
\text { not solely responsible for } \\
\text { this light reflex }\end{array}$ \\
\hline Parafovea & & $\begin{array}{l}\text { Margin, where the ganglion } \\
\text { cell layer, inner nuclear layer, } \\
\text { and Henle layer are thickest } \\
\text { (ie, the retina is thickest) }\end{array}$ & $\begin{array}{l}\text { Ring } 0.5 \mathrm{~mm} \text { in width } \\
\text { surrounding the fovea }\end{array}$ \\
\hline Perifovea & & $\begin{array}{l}\text { From the outermost limit of the } \\
\text { parafovea to the outer limit } \\
\text { of the macula }\end{array}$ & $\begin{array}{l}\text { Ring } 1.5 \mathrm{~mm} \text { in width } \\
\text { surrounding the parafovea }\end{array}$ \\
\hline
\end{tabular}

Macula Anatomical Terminology Table.

Quoted from Retina and Vitreous. American Academy of Ophthalmology. Section 12. 2015-2016

The central retinal artery (the first branch of the ophthalmic artery) enters the eye and divides into 4 branches, each supplying blood to the four quadrants of the retina. These arterial branches are located inside the retina and are divided into small artery branches. The Silio-retina 
artery (a branch of the ciliary artery) will direct the interior of the retina between the optic nerve and the macular center. The retina is supplied by two layers of capillaries, namely the superficial ganglion cell layer and nerve fibers, as well as the inner nucleus layer. Blood is collected from capillaries in the branches of the retinal vein which eventually form the central retinal vein. ${ }^{3,4}$

\section{Visualization of Cross Section and En Face in the Posterior Circulation of the Eye}

Optical coherence tomography angiography (OCTA) is a method for segmenting the retinal layer for an en face display and for producing various composites in flow information both for cross sections and en face visualizations. OCTA is performed using the split-spectrum amplitude-decorellation angiography (SSADA) algorithm on a commercial spectral optical coherence tomography (OCT) (RTVue XR Avanti, Optovue Inc.) system. 5,6

En Face Visualization on Separate Network Plates While OCT began as the dominant cross-section imaging modality, OCTA was clinically used from the start as an En Face imaging modality. OCTA uses predefined techniques for automatic segmentation of anatomic reference fields, such as the inner boundary membrane (ILM) and the outer border of the inner plexiform layer (IPL), the outer plexiform layer (OPL), and the Bruch membrane (BM). The appropriate tissue layer or "slab" can then be defined based on this reference field. Accurate segmentation is important for clinical interpretation. In diseased eyes, pathologies such as drusen, intraretinal cysts, edema, or subretinal fluid can make automatic segmentation less intense. Although significant improvements have been made, expert manual correction is sometimes needed. Software that helps or reduces the workload needed for manually volumetric correction of useful data. ${ }^{5,6}$

Color coding is a common method used to convey additional information. Initially, color was used to convey depth (microns) relative to a simple reference field. Jia et al changed the paradigm so that color was used to represent the flow in different segmented tissue plates. This allows clear visualization of the retinal circulation in the inner retinal plate (between the ILM and the outer border of the OPL) and the choroid circulation in the choroidal plate (under BM) on an angiogram. This division can be further refined, with retinal circulation divided between 2 or more plexuses and choroidal circulation divided into choriocapillaris and inner choroid. Colorcoding based plates allow choroidal neovascularization (CNV), clearly using different colors to represent abnormal flow in the outer retinal plate (between the outer border of OPL and BM).

Angio Vue (Opto-Vue Inc.) is a commercially available OCTA software at a commercially available high speed ( $70 \mathrm{kHz}$ axial scan repeat rate) OCT system (Avanti RT Vue XR, Opto-Vue 


\section{SRIWIJAYA JOURNALOF OPHTHALMOLOGY}

हुरा

Inc.). Using the SSADA algorithm to detect flow, and the orthogonal registration algorithm called motion correction technology to eliminate motion artifacts. Angio-Vue provides a default angiographic display scheme (Figure 5) that defines an en face plate angiography relative to a simplified set of reference planes that can be well segmented by current software. These include ILM, IPL outer boundaries, and "RPE references," which are the most suitable surfaces under RPE and approaching BM positions. For the convenience of Angio-Vue users, 4 default enfaced definitions with display are provided here: 7,8,9

\section{Visualization of Cross Section and En Face on the Anterior of the Eye}

Optical coherence tomography (OCT) provides higher resolution than other non-contact anterior segment imaging modalities. Commercially available OCT systems, either dedicated to anterior eye imaging (such as Visante [Carl Zeiss Meditec Inc.] or Casia [Tomey Corporation]) or hybrid retina / cornea platforms (such as Avanti [Opto-Vue Inc.] or Cirrus [Carl Zeiss Meditec Inc. ]), has been widely used in managing corneal disease, monitoring anterior angular structures, and planning anterior eye surgery. ${ }^{10,11,12}$

Conventional OCT images are only tissue structures. As OCT technology advances, new developments of optical coherence tomography angiography (OCTA) offer precise visualization of intravascular flow without injection of contrast agents (such as fluorescein or indocyanine green). OCTA was initially applied to evaluate the condition of the posterior segment of the eye such as retinopathy or choroidal neovascularization, but the same technology can also be applied to anterior eye angiography.

Healthy corneas should not have blood vessel growth. ${ }^{13}$

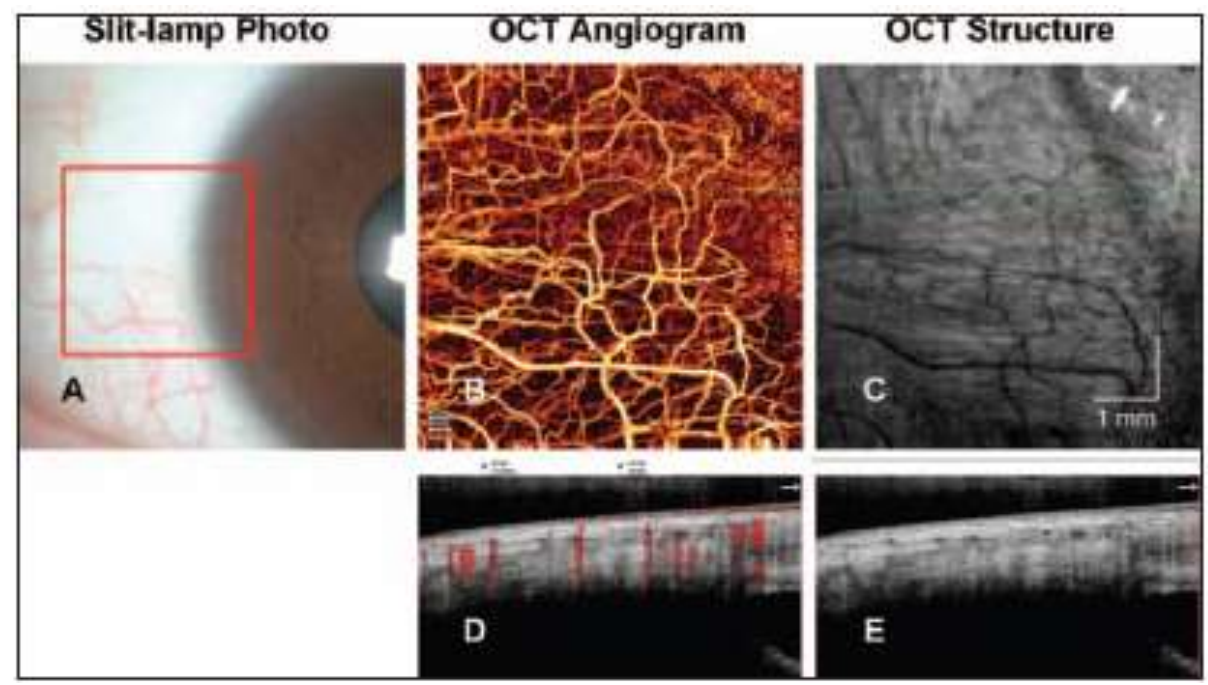




\section{SRIWIJAYA JOURNALOF OPHTHALMOLOGY}

हुण

Image of normal and sclera bulbar conjunctiva. (A) Photograph of a lamp gap. A red box marks the OCT scan area. (B) En face OCT angiogram combined conjunctival and scleral vessels. (C) En face image of OCT structure. (D) Cross-sectional image of OCT overlaid with angiographic signals marked in red. (E) Cross-section OCT image. The location of the cross section OCT image is indicated by a green line on the face OCT.

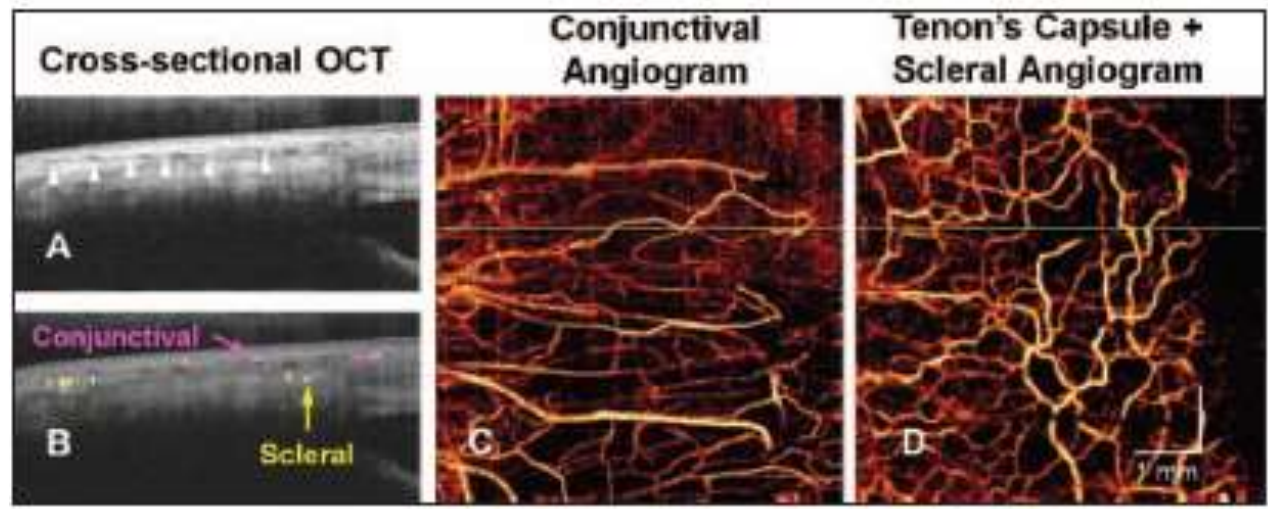

Image of conjunctiva and OCTA sclera. (A) OCT image of cross-section of the limbus. There is a narrow demarcation line (white arrowhead) that separates the conjunctival stroma from the Tenon capsule and the sclera below it. (B) conjunctival (pink) and episcleral (yellow) angiography decided deeper superimposed on a cross-sectional cross-sectionals OCT image. (C) En face of the conjunctival bulbar OCTA. (D) Scleral OCTA. The cross-sectional OCT scan location is represented by green lines in $\mathrm{C}$ and $\mathrm{D}$.

Angiography Optical Coherence Tomography (OCTA) is a functional extension of Optical Coherence Tomography (OCT) which uses variations in signals induced by blood flow as an intrinsic contrast mechanism to distinguish blood vessels from static tissue. This requires taking repeated cross-sectional B-frames in the same position and assessing changes in the OCT signal in each B-frame pixel during multiple scans. Pixels that correspond to blood vessels show fluctuations in OCT signals as a result of the flow of blood cells while static tissue pixels show slight changes. The OCTA algorithm differs in assessing changes and which parts of complex OCT signals (amplitude, phase, or amplitude and phase) are assessed. ${ }^{14,15}$

\section{Conclussion}

Optical Coherence Tomography Angiography (OCTA) is a new high-resolution imaging method for visualizing retinal and choroidal circulation without any dye injection. OCTA is done by using split-amplitude spectrum amplification angiography (SSADA) amplification on one of 
the OCT swept-source prototype or commercial spectral OCT systems (RT Vue-XR Avanti, Opto-Vue, Inc., Fremont, CA). However, in general the principle also applies to other types of OCT angiography.

The use of OCT as a noninvasive clinical tool for evaluating the anatomical structure of the macula and optic nerve. Based on its initial emergence as a research tool in the early 1990s, this has reached its primary clinical use in early 2000 with time domain (TD) technology, but really began after 2005 with the release of the OCT Fourier Domain (FD) or spectral domain (SD), which features a large increase in imaging resolution due to faster scanning speeds along with motion improvement technology, such as eye tracking.

\section{References}

1. Bruno Lumbroso, David Huang, Ching J Chen, et al. Clinical OCT Angiography Atlas. Jaypee Medical Inc. New Delhi. 2015.

2. David Huang, Bruno Lumbroso, Yali Jia, et al. Optical Coherence Tomography Angiography of The Eye. Slack Inc. USA. 2018.

3. Chow, David R, et al. OCT Angiography. Thieme Medical Publishers Inc. New York. 2018.

4. Sylvia Nghiem, Corrine, Gabriel, et al. Practical OCT Angiography. Carl Zeiss. Meditec France SAS. 2010.

5. Kwiterovich KA, Maguire MG, Murphy RP, et al. Frequency of adverse systemic reactions after fluorescein angiography. Results of a prospective study. Ophthalmology. 2001; 98(7): 1139-1142.

6. Wei Jay. Optical Cohorence Tomography Angiography With The AngioVue Imaging System. A Compendium of Scientific Articles and Abstract. Optovue, Inc. France. 2017.

7. Lumbroso B, Rispoli M. Guide To Interpreting Spectral Domain Optical Coherence Tomography. $2^{\text {nd }}$ edition. Jaypee Brothers Medical Publisher. India. 2011.

8. Mohana KP, Das D, Bhende M. Optical Coherence Tomography Angiography: Newer Techniques, Newer Machines. Sci J Med \& Vis Res Foun. Vol xxxiii. Recent advance. June 2015.

9. Drexler W, Fujimoto JG, editors. Optical Coherence Tomography: Technology and Aplication. $2^{\text {nd }}$ edition. Springer. USA. 2015.

10. Kuehlewein L, Sarraf D, Sadda SR. OCT-Angiography in Age-Related Macular Degeneration. Retina Today. California. 2015. 
11. Al Kharousi N, Wali UK. Clinical Applications Of Optical Cohorence Tomography In Ophtalmology. Selected Topics In Optical Coherence Tomography. Intech. Croatia. 2012.

12. Sousa DC, Breda J, Pinto LA. Optical Coherence Tomography Angiography. American Academy of Ophtalmology. 2018.

13. Montero J, Saxena S. Optical Coherence Tomography in Macular Desease and Glaucoma. Jaypee-Highlight Medical Publisher. 2012.

14. Podeleanu. Optical Coherence Tomography Angiography: A Comprehensive Review. Journal Of Microscopy. 2017.

15. Emerson H Joel, Stratus OCT. A Practical Operation Guide. Carl Zeiss Meditec inc. 2008.

16. Marshal, Sbastian. Optical Coherence Tomography: Current Technology and Applications in Clinical and Biomedical Research. Technical University of Denmark. Denmark. 2013.

17. Moestidjab, Novita HD. Optical Coherence Tomography Posterior Segment. Jurnal Oftalmologi Indonesia vol 4 no 3. 2012.

18. Liesegang T.J. et al. Fundamentals and Principles of Ophthalmology. Basic and Clinical Science Course. American Academy of Ophthalmology. Section 2. 2018-2019.

19. Puliafito CJ,et al. Optical Coherence Tomography of Ocular Disease: Principles of Operation and Technology. USA. 2013.

20. Bowling B. Kanski's Clinical Ophtalmology: Retinal Vascular Disease. $8^{\text {th }}$ edition.Elsevier. USA. 2016.

21. Riordan P, Cunningham E. Vaughan \& Asbury's General Ophthalmology. $18^{\text {th }}$ Ed. Mc Graw Hill. 2011.

22. Sasono W, Effendi RD. Idiopathic Macular Hole. Jurnal Oftalmologi Indonesia vol 6 no 3. 2 